\title{
Review Article \\ The Role of Oxidative Stress and Inflammation in Cardiovascular Aging
}

\author{
Junzhen Wu, ${ }^{1}$ Shijin Xia, ${ }^{1}$ Bill Kalionis, ${ }^{2}$ Wenbin Wan, ${ }^{3}$ and Tao Sun ${ }^{1}$ \\ ${ }^{1}$ Shanghai Institute of Geriatrics, Department of Geriatrics, Huadong Hospital, Fudan University, Shanghai 200040, China \\ ${ }^{2}$ Department of Perinatal Medicine, Pregnancy Research Centre and Department of Obstetrics and Gynaecology, \\ University of Melbourne, Royal Women's Hospital, Parkville, VIC 3052, Australia \\ ${ }^{3}$ Department of Neurology, Zhongshan Hospital, Fudan University, Shanghai 200032, China
}

Correspondence should be addressed to Shijin Xia; xiashijinhd@163.com

Received 19 June 2014; Accepted 10 July 2014; Published 20 July 2014

Academic Editor: Alice Santos-Silva

Copyright (C) 2014 Junzhen Wu et al. This is an open access article distributed under the Creative Commons Attribution License, which permits unrestricted use, distribution, and reproduction in any medium, provided the original work is properly cited.

Age is an independent risk factor of cardiovascular disease, even in the absence of other traditional factors. Emerging evidence in experimental animal and human models has emphasized a central role for two main mechanisms of age-related cardiovascular disease: oxidative stress and inflammation. Excess reactive oxygen species (ROS) and superoxide generated by oxidative stress and low-grade inflammation accompanying aging recapitulate age-related cardiovascular dysfunction, that is, left ventricular hypertrophy, fibrosis, and diastolic dysfunction in the heart as well as endothelial dysfunction, reduced vascular elasticity, and increased vascular stiffness. We describe the signaling involved in these two main mechanisms that include the factors NF- $\kappa \mathrm{B}$, JunD, p $66^{\text {Shc }}$, and Nrf2. Potential therapeutic strategies to improve the cardiovascular function with aging are discussed, with a focus on calorie restriction, SIRT1, and resveratrol.

\section{Introduction}

The average age of the world's population is steadily increasing. For example, in the United States, in 2008, the number of people 65 years or older was 38.9 million, which accounts for $12.8 \%$ of the population. By 2030 , that number is predicted to rise to 72.1 million, comprising almost $19 \%$ of the population [1].

Emerging evidence reveals that the rising epidemic of cardiovascular disease (CVD) is fuelled by obesity, hypertension, and diabetes [2]. However, the aging population is also an independent and cumulatively factor in CVD. Aging results in well-defined phenotypic changes, which render the cardiovascular system prone to disease, even in the absence of traditional risk factors [3]. Intrinsic cardiac aging is defined as the slowly progressive age-dependent degeneration and decline in function that make the heart more vulnerable to stress and contribute to increased cardiovascular mortality and morbidity in the elderly [4]. Remarkably, a host of molecular, cellular, structural, and functional alterations that are operative in accelerated arterial aging have also been implicated in the pathogenesis and progression of arterial diseases.

Considerable published evidence shows that with advanced age, production of ROS significantly increases in both the heart [5] and the vasculature [6]. Indeed, there exists an imbalance between the oxidative and antioxidative system that accompanies aging, which culminates in cardiovascular injury. On the other hand, provoked by a continuous antigenic and oxidative stress, a phenomenon appears in the elderly denoted by "inflammaging", which is used to elucidate the low-grade chronic inflammatory state in the aged population [7]. A large body of evidence suggests that low-grade chronic inflammation makes aged individuals more susceptible to age-related disease [8-10], especially CVD [11-13]. In this review, insights gained from oxidative stress and inflammation studies may reveal important aspects of the mechanisms of cardiovascular aging and provide rational approaches to develop novel therapies for age-related cardiovascular disease. 


\section{Changes in the Vasculature with Aging}

Findings from studies of changes in the vasculature that accompany aging in human and animal models support the concept that aging is an independent risk factor for cardiovascular disease [14-17]. Salient features of age-associated changes in the vascular system include luminal dilation, intimal and medial thickening, vascular stiffening, and endothelial dysfunction [18]. Accumulating evidence shows that even in apparently well-aged populations there is increased large artery thickening and stiffness [19], endothelial dysfunction, and ensuing increases in systolic and pulse pressure. These events precede clinical disease and increase the risk of developing clinical atherosclerosis, hypertension, and stroke [20].

2.1. Structural and Functional Changes in the Vasculature with Aging. Age-associated changes in the arterial properties of individuals who are considered otherwise healthy may have relevance to the steep age-dependent increase in vascular diseases. Cross-sectional studies in humans have found that wall thickening and dilatation are prominent structural changes that occur within large elastic arteries during aging [19]. Progressive intima thickening (IM), which can be measured by pulse wave velocimetry (PWV), is usually a risk factor for cardiovascular disease with aging in humans [18]. Furthermore, the degree of IM thickness as a risk factor in other individuals equals or exceeds that of most other conventional risk factors $[18,21]$. Other than stiffness, another prevalent vascular alteration is calcification in the aging population [22].

2.2. Molecular and Cellular Changes in Vasculature with Aging. Insights gained from cellular and molecular studies in aged vasculature help our understanding of the formation and development of cardiovascular disease. Age-associated remodeling of the walls of large arteries of rodents and nonhuman primates is quite similar to that observed in humans. These changes include luminal dilatation, intimal and medial thickening, vascular stiffening, and endothelial dysfunction [20]. The development of physiological aging is subject to the regulation by signaling pathways, which are influenced by endogenous and exogenous factors. At the cellular level, decreased protein synthesis, increased angiotensin II levels, mitochondrial dysfunction, oxidative stress, and altered patterns of calcium regulation as well as increased DNA, protein, and lipid oxidation are held mainly responsible [23].

The thickened intima in older rats is composed of matrix molecules including collagen, proteoglycans, and vascular smooth muscle cells (SMCs), which migrate into the intima from the media in aged vascular systems. Intimal thickening is the key step in the formation of atherosclerosis. Furthermore, the thickened intima exhibits increased immunostaining for transforming growth factor- $\beta$ (TGF- $\beta$ ) and interstitial cell adhesion molecule-1 (ICAM-1) as well as zincdependent endopeptidase type-2 metalloproteinase (MMP2) and its activator, membrane type metalloproteinase-1.
TGF- $\beta$, an important factor for vascular remodeling, is a potent factor in the synthesis of extracellular matrix proteins and is associated with an age-induced increase in arterial fibronectin and collagen [24]. Aging also impairs the intracellular signal transduction system and reduces the activity of nitric oxide (NO), which is derived from the endothelium and exhibits vasodilatory effects [25]. Concurrently, the expression of endothelium-derived NO synthase (eNOS), which influences the production of NO is reduced, whilst expression of cytokines and ICAM increases [26]. Moreover, in aged endothelial cells, increased expression of a cell cycle-controlling factor, senescence-associated $\beta$ galactosidase (SA $\beta$ gal), as well as telomere shortening and inhibition of telomere activity, have all been observed [27].

\section{Changes in the Heart with Aging}

The heart is a vital organ in the body responsible for pumping blood throughout the circulatory system via continuous rhythmic contractions. The proper functioning of the heart is entirely dependent on a constant supply of oxygen and energy. Therefore, it is not surprising that the heart has a limited life span. Indeed, intrinsic cardiac aging, in the absence of other cardiovascular risk factors, has been shown in many species $[3,28,29]$.

There is a continuum of expression of cardiac structural and functional alterations that occurs with age in healthy humans, and these age-associated cardiac changes seem to have relevance to the steep increases in left ventricular hypertrophy (LVH), chronic heart failure, and atrial fibrillation (AF) that are seen with increasing age [30].

3.1. Structural and Functional Changes in the Heart with Aging. Increased left ventricle (LV) wall thickness, alterations in the diastolic filling pattern, impaired LV ejection, and heart rate (HR) reserve capacity as well as altered heart rhythm are the most dramatic changes in cardiac function that occur with aging in healthy persons, when assessing cardiovascular function in healthy adult subjects ranging in the age from 20 to 85 years [30].

\subsection{Cellular and Molecular Changes in Heart with Aging.} The heart is comprised of multiple cell types and tissues, in addition to myocytes, that is, interstitial fibroblasts, matrix and arteries. The number of cardiac myocytes becomes reduced as a result of necrosis and apoptosis, along with enlargement of myocyte size. The expression of atrial natriuretic [31] and opioid peptides [32], molecules that are usually produced in response to chronic stress, is increased in the senescent rodent heart. Coordinated changes in the function or expression of proteins that regulate several key steps in the cardiac cell excitation-contraction coupling process occur in the rodent heart with aging and result in a prolonged action potential (AP), a prolonged cytosolic calcium transient after excitation and a prolonged contraction. This altered pattern of $\mathrm{Ca}$ regulation and myosin protein expression allows 
the myocardium of older hearts to generate force and active stiffness for an extensive period after excitation [24].

\section{Oxidative Stress and Cardiovascular Aging}

4.1. The Relationship between Oxidative Stress and Cardiovascular Aging. First proposed by Harman, in 1956, the free radical theory of aging postulates that the production of intracellular reactive oxygen species is the major determinant of lifespan [33]. Currently, oxidative stress and impaired antioxidant defense mechanisms are believed to be key contributors to the cardiovascular aging process [34]. Oxidative stress develops as a consequence of excessive generation of reactive oxygen species (ROS), by enzymes such as NADPH oxidase, uncoupled nitric oxide synthase, and xanthine oxidase, by the mitochondrial electron transport chain, and as a result of reduced antioxidant capacity [35]. In the vessel wall, the majority of cellular ROS are generated by the mitochondrial oxidative phosphorylation system, which is a vital component of the mitochondrial free radical theory of aging [36]. In the senescent heart, the majority of ROS are derived from NADPH oxidase and the mitochondrial electron transport chain (ETC) [29]. There is substantial evidence supporting the involvement of oxidative stress in the genesis of vascular damage within the aging process. Increased oxidative stress and ROS production, associated with decreased endothelial NO bioavailability, have been detected during the aging process in different vascular beds in various animal models including the rat aorta [37], coronary arteries [38], and mouse aorta [39]. Elevated oxidative stress in the senescent myocardium has several consequences such as enhanced protein oxidation/nitration, reduced bioavailability, lipofuscin formation, activation of inflammatory response, antioxidative stress response, apoptosis, and endoplasmic reticulum (ER) stress [29]. Importantly, superoxide anion $\left(\mathrm{O}_{2}{ }^{-}\right)$reacts with endothelium-derived $\mathrm{NO}$ to form peroxynitrite $\left(\mathrm{ONOO}^{-}\right)$, a potent nitrating and oxidizing agent. There is a growing body of evidence that demonstrates substantially enhanced cardiovascular peroxynitrite $\left(\mathrm{OONO}^{-}\right)$, superoxide anion $\left(\mathrm{O}_{2}^{-}\right)$formation, and decreased NO bioavailability, with aging. Experimental studies show that aging leads to reduced NO production and endothelial dysfunction, regardless of other risk factors [25, 39]. Moreover, another theory posits that the endothelium of aged subjects produces enough NO to reach full relaxation of the mesenteric vasculature, but this $\mathrm{NO}$ is partially counteracted by COX-derived vasoconstricting compounds and reactive oxygen species, probably superoxide anions, which are also produced by endothelial cells [40]. In any case, increased ROS production ultimately initiates the endothelial dysfunction and myocardium damage. Impaired endothelial vasodilation is early manifestations of arterial aging. These impaired processes precede, by years, the clinical manifestations of vascular dysfunction, which are the first step toward cardiovascular disease and influence vascular outcome in the elderly [41].

NO, produced by endothelial NO synthase (eNOS), is the most important vasodilator and is a marker of vascular health. Impaired NO bioavailability is observed in hypertension, diabetes, and atherosclerosis [42]. Aging may impair eNOS functionally via several mechanisms. During the aging process in rat arteries, the expression of eNOS is lowered, resistance to oxidation is weakened, and the response of vascular smooth muscle to NO is apparently decreased [43]. The decreased expression of eNOS that accompanies aging is attributed partly to L-arginine, a major eNOS substrate, which is degraded by arginase II [44]. Interestingly, arginase II activity and expression increase with age, resulting in decreased eNOS availability and reduced NO synthesis and thus contributes to endothelial dysfunction. Besides Larginine, tetrahydrobiopterin (BH4) is an important cofactor for eNOS activity, which is involved in age-related endothelial dysfunction [44]. Indeed, increased oxidative stress rapidly degrades $\mathrm{BH} 4$ leading to altered eNOS efficiency whereas exogenous administration improves endothelium-dependent vasodilation in human aging [45]. Worthy of note is that agerelated eNOS dysfunction is critically involved in microvascular dysfunction and impaired ventricular contractility in elderly patients [46].

\section{Antioxidant Response in Cardiovascular Aging}

As previously stated, oxidative stress may result from increased ROS generation, a defective antioxidant defense system, or both.

5.1. Nrf2 Signaling Associated with Cardiovascular Aging. Among transcription factors involved in the cellular response to ROS generation, nuclear factor erythroid-2 related factor-2 (Nrf2) is an evolutionarily highly conserved redox-sensitive transcription factor that is activated by ROS production in the vasculature of young animals, leading to the upregulation of various antioxidant genes [47]. Despite an increase in superoxide production, aortas from Fischer $344 \times$ Brown Norway rats show that aging results in a progressive increase in $\mathrm{O}_{2}{ }^{-}$ production, as well as downregulation of protein and mRNA expression of Nrf2. Consequently, there is decreased nuclear Nrf2 activity and decreased expression of Nrf2 target genes (i.e., NADPH quinine oxidoreductase-1, glutamylcysteine synthetase, and heme oxygenase-1) [48]. In aging vessels, increased production of ROS fails to activate Nrf2, resulting in increased blood vessel sensitivity to the deleterious effects of ROS [48]. An impairment of the Nrf2 system could contribute to the reduced angiogenic capacity of aged vasculature and its defective response to ischemic injuries, since disruption of Nrf2 signaling impairs angiogenic processes in human coronary arterial endothelial cells [49]. Vascular Nrf2 dysfunction associated with aging would exacerbate cellular oxidative stress and increase the sensitivity of aged vessels to cellular damage. Interestingly, Nrf2 dysfunction exerts proinflammatory effects by exacerbating ROS-mediated NF$\kappa \mathrm{B}$ activation (as described below) in aging [47]. Thus, aging is associated with $\mathrm{Nrf2}$ dysfunction in the vasculature, which likely exacerbates age-related cellular oxidative stress 
and increases sensitivity of aged vessels to oxidative stressinduced cellular damage.

5.2. Superoxide Dismutase Activity. Despite a higher capacity of ROS production in the heart, this organ is well equipped with antioxidant enzymes capable of scavenging free radicals. However, the literature has been controversial about the changes that occur in the antioxidant reserve during cardiac aging, with some studies showing enhanced content and activity [5], whilst others reported no change [50]. An efficient defense mechanism against superoxide radicals produced during oxidative stress is provided by the activity of superoxide dismutase (SOD). The three distinct isoforms of SOD, the cytosolic copper-zinc SOD $(\mathrm{Cu} / \mathrm{Zn}$ SOD, SOD-1), mitochondrial manganese (MnSOD, SOD2 ), and extracellular SOD (EcSOD, SOD-3), have evolved as the key enzymatic system for converting oxygen radicals to hydrogen peroxide and molecular oxygen [51]. MnSOD is the main antioxidant enzyme that scavenges superoxide anions in the inner mitochondrial matrix and acts as a first line of defense against mitochondrial oxidative stress [52]. Studies conducted in MnSOD-deficient mice demonstrate the detrimental effect of superoxide anions and therefore of ROS in mitochondria [53]. Several studies reported decreased expression of MnSOD antioxidant enzyme in aortas of old mice [54]. In humans, while some authors have not observed an alternation in MnSOD expression in endothelial progenitor cells with aging [55], others have demonstrated a decrease of this enzyme's expression in endothelial cells of sedentary aged subjects [56]. The role of $\mathrm{Cu} / \mathrm{ZnSOD}$ is to limit the increase in superoxide and therefore to maintain normal endothelial vasodilation in vascular vessels. In humans, a reduction in $\mathrm{Cu} / \mathrm{ZnSOD}$ protein expression and total SOD enzymatic activity were observed in aged mesenteric lymphatic vessels [57]. The ecSOD is the major SOD isoform in the vascular extracellular space, thereby protecting it against NO inactivation by free radicals during its diffusion to smooth muscle [58]. Reduced mRNA levels of ecSOD, but not $\mathrm{Cu} / \mathrm{ZnSOD}$ or $\mathrm{MnSOD}$, were reported in aged mice when compared with younger mice [59].

\section{Gene Regulation of Transcription}

6.1. JunD Signaling Is Involved in Endothelial Dysfunction. Activator protein-1 (AP-1) is a collection of dimeric complexes made by different members of three families of DNAbinding proteins; Jun, Fos, and ATF/CREB [60]. JunD is the most recently discovered gene of the Jun family. JunD regulates cell growth and survival and protects against oxidative stress by modulating genes involved in antioxidant defense and ROS production [61]. There is a conspicuous link between the deletion of the JunD gene, ROS generation, and endothelial dysfunction. Evidence has been presented for increased ROS generation in immortalized JunD ${ }^{-/-}$cells [62]. Furthermore, gene expression profiling of $\mathrm{JunD}^{-/-}$cells showed downregulation of several free radical scavenging enzymes associated with an increase in the expression of ROS-producing NADPH oxidase [63]. Interestingly, evidence that JunD may be a critical regulator of vascular homeostasis was obtained by investigating its role in ROS-driven vascular aging [63]. Young JunD ${ }^{-1-}$ mice showed an impairment of endothelium-dependent relaxation, as a result of acetylcholine stimulation, that was similar to that observed in aged WT mice, suggesting premature endothelial aging in animals lacking the AP-1 transcription factor JunD. Moreover, JunD overexpression performed by intravenous injection of a predesigned JunD cDNA clone improved acetylcholinedependent relaxation compared with vector-treated mice. Therefore, aged mice showed a downregulation of JunD expression compared with younger animals. Together with diminished expression, it was also reported that JunD transcriptional activity is reduced in aged vessels [63]. Oxidative stress in JunD ${ }^{-/-}$mice was associated with early features of vascular aging, including reduced telomerase activity, increased $\beta$-galactosidase staining, and upregulation of the senescence markers p53 and p16 ${ }^{\text {INK4a }}$ [63]. Finally, JunD protein levels are decreased in patients with end-stage heart failure suggesting that the transcription factor may protect against age-related cardiac dysfunction [64].

6.2. The $p 66^{\text {Shc }}$ Signaling Pathway in Endothelial Dysfunction. p $66^{\text {Shc }}$ functions in the intracellular pathway that converts intracellular oxidative signals into apoptosis. Multiple lines of evidence implicate $\mathrm{p} 66^{\text {Shc }}$ in aging and in the pathogenesis of aging-associated diseases in mammals [39]. Intracellular free radicals are reduced in cells lacking the $\mathrm{p} 66^{\mathrm{Shc}}$ gene ( $666^{\text {Shc-l- }}$ cells), and both systemic as well as intracellular free radicals are diminished in $\mathrm{p} 66^{\text {Shc- } /-}$ mouse models exposed to high oxidative stress [65]. Accordingly, mice lacking the $\mathrm{p} 66^{\text {Shc-l- }}$ gene display a prolonged lifespan as well as increased resistance to oxidative stress and apoptosis. $\mathrm{p} 66^{\text {Shc-l- }}$ signaling is required to induce a ROS-driven vascular senescent phenotype [39]. Importantly, $\mathrm{p} 66^{\text {Shc }}$ activation is thought to be upstream of NADPH and to be a mammalian target of the rapamycin (mTOR) pathway, two important determinants of vascular damage [66]. p66 $6^{\text {Shc- }-}$ mice showed increased NO bioavailability and decreased production of superoxide $\mathrm{O}_{2}{ }^{-}$, compared with WT aged mice [39]. Indeed, diabetic p $66^{\text {Shc- } /-}$ mice were protected against myocardial oxidative stress, apoptosis, and telomere shortening [67]. Moreover, ablation of the $\mathrm{p} 66^{\mathrm{Shc}}$ gene in cardiac stem cells preserved the growth reserve of the heart [67]. The clinical relevance of p $66^{\text {Shc }}$ is supported by the notion that $\mathrm{p} 66^{\text {Shc }}$ gene expression is increased in mononuclear cells obtained from patients with type 2 diabetes and coronary artery disease [68]. Most important is that $\mathrm{p} 66^{\text {Shc }}$ is part of a signal transduction pathway relevant to endothelial integrity. The long-lived p $66^{\text {Shc- }- \text { mice }}$ are protected against age-related endothelial dysfunction [39].

\section{Inflammation in Cardiovascular Aging}

ROS, as mentioned above, is produced increasingly with age as a result of a variety of stimuli including physical, 
chemical, and biological agents. These factors predispose to endothelial dysfunction and cellular damage that lead to the process of aging. Interestingly, emerging evidence provides a close link between oxidation and inflammation, since excessive or uncontrolled free radical production can induce an inflammatory response and free radicals are inflammation effectors [69]. Indeed, a low level of chronic inflammation is associated with most age-related diseases including atherosclerosis, cardiovascular diseases, and diabetes [70]. This phenomenon is provoked by continuous antigenic load and stress and is accompanied by a global reduction in the capability to cope with a variety of stressors as well as a concomitant, progressive increase in proinflammatory status [7]. The term "inflammaging" was coined by Franceschi et al. to denote the upregulation of the inflammatory response with progressing old age and the ensuing low-grade chronic systemic proinflammatory state that underlies most ageassociated diseases [7].

7.1. The Role of Inflammation in Cardiovascular Aging. Aging is accompanied by immune, hormonal, and adipose changes leading to a chronic inflammatory state. Inflammation may constitute a biological foundation for the pathophysiological process of frailty. These changes influence the onset of frailty and cognitive decline as well as cardiological, neurological, and vascular events. However, inflammation is not a negative phenomenon perse, since it is needed to maintain life through a constant struggle to preserve the integrity of the individual. Importantly, if the levels of inflammatory compounds exceed the control of anti-inflammatory compounds, an imbalance occurs and an inflammatory state is established [70]. Still under debate is the precise cause that underlies the low-grade inflammatory process associated with aging which leads to the development of the age-related inflammatory chronic diseases such as atherosclerosis [71] and hypertension [72]. A current hypothesis is that chronic stimulation of the immune system contributes to the proinflammatory shift $[73,74]$. Multiple lines of evidence demonstrate that aging is commonly accompanied by a progressive deregulation of the immune response, mainly due to alterations of the cellular/adaptive immune response, especially $\mathrm{T}$ cell responses [73]. Compared with these changes in cellular immunity, some features of innate immunity are relatively well maintained with age [73]. Thus, this apparent disequilibrium between the retention of relatively reactive innate immune response with aging leads to the presence of a low-grade inflammatory status commonly present in the elderly. The cause of this is certainly multifactorial. One of the likely principal causes is chronic antigenic stimulation by cytomegalovirus (CMV), bacteria, and other viruses or endogenous cellular factors such as posttranslationally modified macromolecules, including DNA, or proteins that can be modified or continuously released from tissues such as the elastin peptides (EPs) [71]. These modifications may also result in chronic stimulation of adaptive immune responses, recognized by an inverted $\mathrm{CD} 4$ : $\mathrm{CD} 8$ ratio that is caused by an overwhelming expansion of CD8 + cells [74]. The processes described above are thought to culminate in the chronic low-grade inflammatory process that accompanies aging.

Low-grade systemic inflammation characterized by the elevation of circulating acute-phase proteins and proinflammatory cytokines is associated with frailty as well as the development and progression of severe, age-related conditions such as cardiovascular disease (CVD). Atherosclerosis/atherothrombosis is the major cause of the rising epidemic of CVD. Just three decades ago, atherosclerosis was envisaged as a bland proliferative process [75]. Multiple independent pathways of evidence now pinpoint inflammation as a key regulatory process that links multiple risk factors for atherosclerosis and its complications with altered arterial biology [76]. The endothelium, the inner lining of all blood vessels, maintains homeostasis through a balance of endothelium-derived factors. Disruption by inflammatory and traditional cardiovascular risk factors leaves the vasculature susceptible to atherogenesis, the process of forming plaques in arteries. Inflammatory mediators play a fundamental role in the initiation, progression, and eventual rupture of atherosclerotic plaques. TNF- $\alpha$ activates a proinflammatory gene expression profile in endothelial cells that promotes adherence of monocytes and their migration into the subendothelial layer. At a molecular level, E-selectins mediate leukocyte rolling, whereas chemokines lead to leukocyte activation, whilst intercellular adhesion molecule- 1 and vascular cell adhesion molecule-1 contribute to leukocyte adhesion. In the vasculature, monocytes undergo transformation into macrophages that internalize modified lipoproteins and give rise to foam cells. In parallel, upregulation of hemostatic proteins induces a highly procoagulative state of activated endothelium. The evolution of a fatty streak towards a complex atherosclerotic lesion is characterized by amassed oxidized low-density lipoproteins (LDLs) exerting toxic effects on macrophages and smooth muscle cells (SMCs), which culminates in the formation of a necrotic core [77]. In this process, SMCs migrate from the tunica media into the intima via degradation of the extracellular matrix, which is mediated by MMP-9 as well as other proteinases [78]. In the intima, SMCs proliferate under the influence of various growth factors and secrete extracellular matrix proteins, including interstitial collagen, especially in response to transforming growth factor- $\beta$ (TGF- $\beta$ ) and platelet-derived growth factor. These molecular processes cause the lesion to evolve from a lipid-rich plaque to a fibrotic and then calcified plaque, which may create a stenosis [79]. Acute thrombotic complications such as atherothrombosis can result in vessel occlusion and the restriction in blood flow may trigger the manifestation of disease, heart attacks. We have emphasized that endothelial dysfunction is an early hallmark of vascular disease that can occur well before the structural manifestation of atherosclerosis. Endothelial dysfunction can serve as an independent predictor of future cardiovascular episodes and we highlighted the vital role that inflammation plays in initiating many of the adverse events. Indeed, increased arterial stiffness, as revealed by a greater pulse pressure and pulse wave velocity (PWV), has been associated with many cardiovascular risk factors and is reflected by raised inflammatory biomarkers such as high 
C-response protein levels [21]. Notably, increasing evidence links inflammatory processes to atherogenesis. Markers of inflammatory activation and endothelial dysfunction provide useful information about a patient's risk and stage of developing cardiovascular disease, as described below.

In humans, considerable evidence supports that essential hypertension is a condition of chronic low-grade inflammatory status [80, 81]. Evidence of immune system involvement in the vasculature from patients with hypertension or cardiovascular disease is beginning to appear in the literature. Inflammation participates in many processes that contribute to the development of elevated blood pressure (BP). In the vasculature, inflammation can enhance the proliferation of smooth muscle cells and play a role in vascular remodeling [80]. In animal models of hypertension, there is evidence of infiltration of inflammatory cells from the innate immune system (i.e., dendritic cells, NK cells, monocytes, and macrophages) in perivascular fat and adventitia of blood vessels as well as in other target organs (i.e., kidney and heart) [81]. Osteopetrotic mice have a mutation in the macrophage colony-stimulating factor (Csfl) gene and thereby have macrophages that are functionally deficient. Osteopetrotic mice remain normotensive and develop less endothelial dysfunction, vascular remodeling, and oxidative stress, despite infusion of angiotensin II (Ang-II) [82] or deoxycorticosterone acetate (DOCA) salt treatment [83], compared with wild-type littermates. Together, these studies suggest a role for macrophages in the pathogenesis of hypertension and vascular damage. Monocytes and macrophages express functional Ang-II and mineralocorticoid (MR) receptors, the activation of which lead to ROS generation via activation of NADPH oxidase and cytokines [13]. Monocyte and macrophage-derived vascular ROS may upregulate the expression of chemokines and adhesion molecules, reduce NO bioavailability, stimulate VSMCs hypertrophy, and activate matrix metalloproteinases leading to vascular dysfunction and remodeling $[84,85]$. Furthermore, Treg cells involved in adaptive immunity produce IL-10, a significant anti-inflammatory cytokine that exerts an effect on the improvement of microvascular endothelial function in hypertension [72]. Aortic stiffness, measured by carotidfemoral PWV, constitutes a hallmark of the aging process and is an independent predictor of adverse cardiovascular events in hypertension [86]. Indeed, low-grade inflammation in conjunction with hypoadiponectinemia exerts an additive detrimental effect on aortic stiffness thereby accelerating the vascular aging process [87]. However, it is not evident whether vascular inflammation causes the arterial stiffening and hypertension or it is a consequence of high blood pressure stiffening the arteries that favors a cascade which culminates in vascular inflammation and increased arterial stiffness.

Arterial fibrillation (AF) is the most common cardiac arrhythmia and its prevalence in the general population is increasing rapidly [88]. An analysis from the Framingham Heart Study reports that the associations could be due to in part the well-established associations between inflammation and prevalent cardiovascular conditions that predispose to AF [89]. Conen et al. provide evidence that inflammation, which is measured by plasma levels of high-sensitivity Creactive protein, sICAM-1, and fibrinogen, is significantly associated with AF events in a female population without a history of cardiovascular disease and where traditional risk factors were controlled for [90]. These findings suggest that inflammation may be involved in the pathogenesis of AF. A substantial body of evidence reveals that patients with rheumatoid arthritis (RA) have an increased risk of coronary heart disease, an increased standardized mortality ratio, and a shortened life expectancy by 3-18 years when compared with the matched non-RA population [91]. An abundance of data identifies enduring systemic inflammation as the pathophysiological basis for linking RA to accelerated heart disease development. Although the specific pathophysiological link between systemic inflammation and cardiovascular disease is not completely clear, the promotion of accelerated coronary atherosclerosis is considered the most important mechanism for the higher prevalence of ischemic heart disease (IHD) in RA [92]. In fact, systemic release of proinflammatory cytokines (IL-1, IL-6, and TNF- $\alpha$ ) in RA synovial tissue could boost the immunoinflammatory process underlying atherogenesis either directly by affecting the cells of the plaque or indirectly by stimulating a number of proatherogenic functions of liver, adipose tissue, skeletal muscle, and vascular endothelium [93]. A plethora of data investigating HIV-positive patients demonstrates increased coronary arterial disease rates compared with a non-HIV population, particularly among women [94, 95]. Nordell et al. [96] assessed the prognostic value of inflammatory and coagulation markers with respect to fatal outcomes among patients with HIV who experience CVD events. Their findings suggest that chronic inflammation and activated coagulation associated with HIV lead to a poor outcome when CVD event occurs.

\subsection{Predictors of Cardiovascular Disease That Are Involved} in Inflammation. As mentioned above, inflammation plays an important role in cardiovascular disease. The immune system produces more proinflammatory cytokines under the chronic stimulus that accompanies aging. Knowledge has flourished regarding the predictive value of several inflammatory markers, on the incidence of cardiovascular events, even in the apparently well healthy population [9799]. Among the inflammatory markers, interleukin-6 (IL6), C-reactive protein (CRP), and TNF- $\alpha$ have generated considerable attention. Over 15 years ago, an association between enhanced inflammations, as demonstrated by higher plasma levels of CRP in middle-aged men without previous cardiovascular disease, was reported using data from the Multiple Risk Factor Intervention Trial (MRFIT) [100]. Lowdensity lipoprotein (LDL) is the focus of current guidelines for the determination of the risk of cardiovascular disease [101]. Ridker et al. [102] conducted a study to determine whether CRP is a stronger predictor of future cardiovascular events than LDL cholesterol. Findings from the Health ABS Study [103] indicate that IL-6, TNF- $\alpha$, and CRP markers predicted the onset of cardiovascular events. Individuals with 
high levels of the three markers had the greatest risk of cardiovascular events. Moreover, increased IL-6 levels were the strongest and most consistent risk factor for cardiovascular events. According to this study, IL- 6 and TNF- $\alpha$ showed more consistent results than CRP in predicting cardiovascular events. Concomitantly, it was suggested that TNF- $\alpha$ and IL-6 are associated with the severity of left ventricular dysfunction and with the degree of activation of the sympathetic and renin-angiotensin systems [11]. In humans, many lines of evidence that established essential hypertension as a condition of chronic low-grade inflammatory status also revealed a strict and independent association between CRP, TNF- $\alpha$, and IL- 6 or adhesion of molecules and vascular changes in essential hypertensive patients [72]. Therefore, HIV-positive patients with higher levels of inflammatory markers, that is, IL-6 and hsCRP, showed an increased risk of more fatal CVD events [96]. Worth noting is that further studies are needed to determine whether inflammatory markers might represent valid targets for new medications that modify the atherosclerosis process and prevent cardiovascular disease.

7.3. The Inflammatory Phenotype of Senescent Cells. As stated above, a common feature of aging tissues is low-grade chronic inflammation, termed "inflammaging" that may derive partly from an age-related decline in homeostatic immune function or resistance to endogenous microbes. Nevertheless, chronic inflammation may also derive in part from senescent cells, and proteases, termed the senescence-associated secretory phenotype (SASP). The SASP, through the inflammatory, growth-promoting, and remodeling factors that it produces, can potentially explain how senescent cells alter tissue microenvironments, attract immune cells, and unexpectedly induce malignant phenotypes in nearby cells [103]. Proteins that are associated with the SASP, such as TNF- $\alpha$, IL-6, MMPs, monocyte chemoattractant protein-1(MCP-1), and IGF binding proteins (IGFBPs), increase in multiple tissues with chronological aging and occur in conjunction with systemic inflammation [104].

Endothelial dysfunction, vascular smooth cell (VSMC) proliferation/invasion/secretion, matrix fragmentation, collagenization, and glycation are characteristics of an ageassociated arterial phenotype that creates a microenvironment enriched in reactive oxygen species (ROS) needed for the pathogenesis of arterial disease. This niche creates an age-associated arterial secretory phenotype (AAASP), which is orchestrated by the concerted effects of numerous agemodified angiotensin II signaling molecules. The arterial wall is remodeled by the joint effects of fluctuating levels of numerous proteins [105]. Age dramatically alters the volume and contents of the arterial intima in rats, nonhuman primates, and humans [18], which was described above. Small, disoriented vascular smooth muscle cells (VSMCs) and collagen type I and type III markedly increase within the thickened intimae of old rats [106]. Molecular elements of the Ang-II signaling cascade are upregulated in aged arterial walls and play a causal role in arterial aging and in vessel disease [27]. The levels of transcription, translation, and activity of MMP-2 are enhanced within the arterial wall with aging [20]. TGF- $\beta$, VSMCs, and senescence-associated $\beta$-gal activity also vary with aging. The novel AAASP concept provides an explanation for the observation that the arterial wall of younger animals, in response to experimental induction of low-grade chronic inflammation by hypertension or early atherosclerosis, is transformed into a phenotype that is strikingly similar to that which develops during aging [107].

7.4. NF- $\kappa B$ Signaling Regulation in Cardiovascular Aging Associated with Inflammation. NF- $\kappa \mathrm{B}$, an important transcription factor, is regarded as a molecular switch of inflammatory pathways. It is responsible for regulating the gene expression of factors that control cell adhesion, proliferation, inflammation, redox state, and tissue specific enzymes [108]. The $\mathrm{NF}-\kappa \mathrm{B}$ signaling pathway may regulate inflammaging [109]. Indeed, activation of NF- $\kappa \mathrm{B}$ mediates vascular and myocardial inflammation in metabolic and age-related diseases [110]. However, the longevity gene, SIRT1, can be combined with a subunit of NF- $\kappa \mathrm{B}, \mathrm{Rel} / \mathrm{p} 65$ to generate $\mathrm{K} 310$ deacetylase, which inhibits the transcriptional activity of NF- $\kappa \mathrm{B}[111,112]$. $\mathrm{NF}-\kappa \mathrm{B}$ can enforce aging, whereas SIRT1 may regulate NF$\kappa \mathrm{B}$ to delay aging [113]. NF- $\kappa \mathrm{B}$ can regulate both aging and inflammation [114] and it can also inhabit inflammatory reaction by regulating SIRT1 (Sir2 homolog) and FoxO (DAF-1) [109].

MicroRNAs (miRs) are a broad class of small, noncoding RNAs that have revolutionized our understanding of gene transcription and translation. Recent data show that miR regulation entails far more complex posttranscriptional control, with the ability to both repress and activate gene expression by interacting with complementary sequences in coding and noncoding regions of their mRNA targets [115]. Moreover, most of the miRs targeting the NF- $\kappa$ B pathway and its modulators affect NF- $\kappa \mathrm{B}$ signaling dynamics primarily through a negative feedback loop aimed at restraining the excessive proinflammatory response induced by signaling activation [116]. An altered expression of the miRs targeting the NF- $\kappa \mathrm{B}$ pathway may thus contribute to the dysregulation of the inflammatory/anti-inflammatory balance, promoting carcinogenesis [117]. Interestingly, it has recently been observed that miRs can act as agonists of single-stranded RNA-binding Toll-like receptors (TLRs) both in NF- $\kappa \mathrm{B}$ signaling activation and interleukin secretion, thus triggering a proinflammatory response that can promote the creation of a microenvironment favorable to cancer development [118]. Therefore, it is possible that senescent cells contribute to inflammation not only by producing proinflammatory and proangiogenic molecules typical of SASP but also by transferring miRs into other proinflammatory cells, namely, macrophages [119].

In addition, a recent study clearly showed that endothelial suppression of $\mathrm{NF}-\kappa \mathrm{B}$ prolongs the lifespan of mice and ameliorates obesity-induced endothelial insulin resistance [120]. Impaired insulin signaling is indeed an important 
hallmark linking metabolic disease with premature aging of the cardiovascular system [121]. Moreover, age-dependent NF- $\kappa$ B activation was associated with systemic inflammation and impaired endothelial dependent vessel dilation [122]. All these finding validate NF- $\kappa \mathrm{B}$ as a therapeutic target to prevent cardiac disease in elderly.

\section{Therapeutic Implications Involved in Inflammation and Oxidation}

8.1. Caloric Restriction. Caloric restriction (CR) is a dietary regimen, which improves health and slows the aging process in evolutionarily distant organisms by limiting dietary energy intake [123]. There is increasing epidemiological and experimental evidence that CR plays an important role in vasoprotection in aging and in pathological conditions associated with accelerated vascular aging [124]. The mechanisms underlying the beneficial cardiovascular effects of CR are multifaceted and include normalization of mitochondrial biogenesis, attenuation of mitochondrial ROS production, increased bioavailability of $\mathrm{NO}$, and consequential inhibition of signaling pathways regulated by mitochondria-derived ROS. The cellular pathways involved in mitochondrial protection induced by calorie restriction appear to depend on increased expression/activity of the $\mathrm{NAD}^{+}$-dependent histone deacetylase SIRT1 [111]. Expression of SIRT1 in mice confers vasoprotection, reduces endothelial ROS production, inhibits NF- $\kappa$ B signaling, and attenuates vascular inflammation, thus mimicking the effects of CR [125]. Furthermore, evidence supports that aortic mTOR signaling was increased with aging in mice but maintained at young adult levels with CR [126]. In addition, CR can also activate the transcription factor Nrf2, which controls the expression of numerous ROS detoxifying and antioxidant genes involved in regulation of mitochondrial redox homeostasis [127].

A recent study of mice demonstrated that CR can prevent, or significantly lessen, multiple adverse features of arterial aging, as well as age-related increases in arterial blood pressure [126]. The research extended insight into the physiological benefits of CR by providing the first direct evidence that CR partially, or completely, prevents large elastic artery stiffening, wall hypertrophy, endothelial dysfunction, reduction in NO bioavailability and increases arterial blood pressure associated with aging in mice [126].

8.2. SIRT1. Increasing evidence shows that sirtuins, a conserved family of proteins, mediate a large number of the beneficial effects of $\mathrm{CR}[126,128]$. Sirtuins function as $\mathrm{NAD}^{+}$-dependent deacetylases, which are also called class III histone deacetylases (HDAC). SIRT1 in mammals, the closest homologue of the yeast Sir2 protein, is considered to be a novel antiaging protein involved in the regulation of cellular senescence/aging and inflammation. The mechanism of SIRT1-mediated protection against inflammaging involves the regulation of inflammation, premature senescence, telomere attrition, senescence-associated secretory phenotype, and DNA damage response [129]. SIRT1 upregulation, induced by CR, was also attenuated in eNOS $^{-/-}$mice, which indicated that NO derived from eNOS played an important role in SIRT1 expression [130]. Indeed, eNOS acts as a direct substrate for SIRT1. In summary, SIRT1 deacetylates eNOS and increase its activity. The inference is that mechanisms of SIRT1 antiaging effect lie partly in its beneficial role of reducing oxidative stress and improving endothelial function. As explained above, SIRT1 can directly inhibit the activity of NF- $\kappa \mathrm{B}$ signaling by deacetylating RelA/p65 [111]. Worth mentioning is that the aggravated inflammation in vascular aging was inversely related to the expression of SIRT1, whereas CR upregulated SIRT1 expression [131]. There is confirmation that SIRT1 modulates vascular cell senescence during vascular aging [132]. Indeed, senescent endothelial cells were observed in the coronary arteries of patients with ischemic heart disease. The inhibition of SIRT1 by sirtinol leads to increased p53 acetylation, increased PAI-1 expression, and decreased eNOS activity in HUVECs and induces senescence-like behavior including flattened and enlarged cell morphology, increased SA- $\beta$-gal activity, and growth arrest [132]. The exacerbated senescence was accompanied by SIRT1 downregulation, increased p53 acetylation, and p21 expression. In addition, SIRT1 overexpression attenuated high-glucose-induced senescence in HUVECs, whereas SIRT1 inhibition had the opposite effect [132]. Interestingly, SIRT1 can also affect atherosclerosis. Worthy of note is that the endothelium-specific overexpression of SIRT1 decreased atherosclerosis in apoE ${ }^{-/-}$mice [133]. Taken together, improving the function of the cardiovascular system by modulating SIRT1's activity is vitally important. Clinical trials of SIRT1 and its activators will help to bring this promising therapeutic target to reality.

8.3. Resveratrol, Activator of SIRT1. Resveratrol, a diet-derived polyphenol, is a prototype of a new class of drugs referred to as CR mimetics, which are being developed to reverse organ pathologies associated with aging and metabolic diseases [134]. The "French paradox", which describes the phenomenon that morbidity and mortality of coronary artery disease are low in southern France and other Mediterranean territories, is at least partly attributable to resveratrol, which is an important constituent of Mediterranean diets and is involved in vasculoprotection [135]. Resveratrol is thought to have diverse antiatherogenic activities, such as the inhibition of LDL oxidation and platelet aggregation and regulation of vascular smooth muscle proliferation [136, 137]. Multiple lines of evidence indicate that resveratrol inhibits endothelial activation and monocyte adhesion and attenuates proinflammatory gene expression by inhibition of NF- $\kappa \mathrm{B}$ activation in coronary arterial endothelial cells [138]. Indeed resveratrol, a SIRT1 activator, was associated with upregulation of eNOS and induction of specific mitochondrial biogenesis factors, which exert a vasoprotective effect [139]. These studies raise the possibility that resveratrol supplementation may confer significant vasoprotection in elderly humans. 


\section{Conclusion}

With a keen awareness that aging is an independent risk factor for cardiovascular disease, the means by which to achieve successful cardiovascular aging whilst decreasing the risk of CVD is a worthy pursuit. Oxidative stress and inflammation play a vital role in the process of cardiovascular aging. Endothelial dysfunction that is associated with oxidative stress and inflammation is a fundamental feature of CVD. Moreover, the relationship between oxidative stress and inflammation is bidirectional. A better understanding of the molecular and cellular mechanisms underlying cardiovascular aging, as well as their potential interactions, will provide a growing list of potential targets for specific interventions aimed at preventing or delaying the cardiovascular dysfunction associated with aging. Breakthroughs in achieving successful cardiovascular aging that focus on oxidative stress and inflammation are on the horizon.

\section{Conflict of Interests}

The authors declare that there is no conflict of interests.

\section{Acknowledgment}

This work was supported by National Natural Science Foundation of China (Grant no. 31171129).

\section{References}

[1] G. A. Beller, "The cost of our aging population," Journal of Nuclear Cardiology, vol. 17, no. 3, pp. 345-346, 2010.

[2] M. H. Favarato, P. Mease, C. R. Goncalves et al., "Hypertension and diabetes significantly enhance the risk of cardiovascular disease in patients with anthritis," Clinical and Experimental Rheumatology, vol. 32, no. 2, pp. 182-187, 2014.

[3] E. G. Lakatta, "Cardiovascular aging in health," Clinics in Geriatric Medicine, vol. 16, no. 3, pp. 419-443, 2000.

[4] S. V. Brodsky, O. Gealekman, J. Chen et al., "Prevention and reversal of premature endothelial cell senescence and vasculopathy in obesity-induced diabetes by ebselen," Circulation Research, vol. 94, no. 3, pp. 377-384, 2004.

[5] S. Judge, M. J. Young, A. Smith, T. Hagen, and C. Leeuwenburgh, "Age-associated increases in oxidative stress and antioxidant enzyme activities in cardiac interfibrillar mitochondria: implications for the mitochondrial theory of aging," The FASEB Journal, vol. 19, no. 3, pp. 419-421, 2005.

[6] Z. Ungvari, Z. Orosz, N. Labinskyy et al., "Increased mitochondrial $\mathrm{H}_{2} \mathrm{O}_{2}$ production promotes endothelial NF- $\kappa \mathrm{B}$ activation in aged rat arteries," American Journal of Physiology-Heart and Circulatory Physiology, vol. 293, no. 1, pp. H37-H47, 2007.

[7] C. Franceschi, M. Bonafè, S. Valensin et al., "Inflamm-aging. An evolutionary perspective on immunosenescence," Annals of the New York Academy of Sciences, vol. 908, pp. 244-254, 2000.

[8] G. Paolisso, M. R. Rizzo, G. Mazziotti et al., "Advancing age and insulin resistance: role of plasma tumor necrosis factor- $\alpha$," American Journal of Physiology, vol. 275, no. 2, part 1, pp. E294E299, 1998.
[9] G. Candore, C. Caruso, E. Jirillo, T. Magrone, and S. Vasto, "Low grade inflammation as a common pathogenetic denominator in age-related diseases: novel drug targets for anti-ageing strategies and successful ageing achievement," Current Pharmaceutical Design, vol. 16, no. 6, pp. 584-596, 2010.

[10] D. B. Reuben, A. I. Cheh, T. B. Harris et al., "Peripheral blood markers of inflammation predict mortality and functional decline in high-functioning community-dwelling older persons," Journal of the American Geriatrics Society, vol. 50, no. 4, pp. 638-644, 2002.

[11] M. Cesari, B. W. J. H. Penninx, A. B. Newman et al., "Inflammatory markers and onset of cardiovascular events: results from the Health ABC study," Circulation, vol. 108, no. 19, pp. 23172322, 2003

[12] S. Volpato, J. M. Guralnik, L. Ferrucci et al., "Cardiovascular disease, interleukin-6, and risk of mortality in older women: the women's health and aging study," Circulation, vol. 103, no. 7, pp. 947-953, 2001

[13] E. L. Schiffrin, "Immune mechanisms in hypertension and vascular injury," Clinical Science, vol. 126, no. 4, pp. 267-274, 2014.

[14] S. S. Najjar, A. Scuteri, and E. G. Lakatta, "Arterial aging: is it an immutable cardiovascular risk factor?" Hypertension, vol. 46, no. 3, pp. 454-462, 2005.

[15] T. Niccoli and L. Partridge, "Ageing as a risk factor for disease," Current Biology, vol. 22, no. 17, pp. R741-R752, 2012.

[16] B. J. North and D. A. Sinclair, "The intersection between aging and cardiovascular disease," Circulation Research, vol. 110, no. 8, pp. 1097-1108, 2012.

[17] V. Chan, A. Fenning, S. P. Levick et al., "Cardiovascular changes during maturation and ageing in male and female spontaneously hypertensive rats," Journal of Cardiovascular Pharmacology, vol. 57, no. 4, pp. 469-478, 2011.

[18] E. G. Lakatta and D. Levy, "Arterial and cardiac aging: major shareholders in cardiovascular disease enterprises: part I: aging arteries: a "set up" for vascular disease," Circulation, vol. 107, no. 1, pp. 139-146, 2003.

[19] E. G. Lakatta, "Cardiovascular regulatory mechanisms in advanced age," Physiological Reviews, vol. 73, no. 2, pp. 413-467, 1993.

[20] M. Wang and E. G. Lakatta, "Altered regulation of matrix metalloproteinase-2 in aortic remodeling during aging," Hypertension, vol. 39, no. 4, pp. 865-873, 2002.

[21] G. F. Mitchell, "Arterial stiffness and wave reflection: biomarkers of cardiovascular risk," Artery Research, vol. 3, no. 2, pp. 56-64, 2009.

[22] F. Paneni, S. Costantino, F. Cosentino, and T. F. Lüscher, "Mechanisms of cardiovascular aging," Current Translational Geriatrics and Experimental Gerontology Reports, vol. 2, no. 4, pp. 275-283, 2013.

[23] C. Rammos, U. B. Hendgen-Cotta, and R. Deenen, "Age-related vascular gene expression profiling in mice," Mechanisms of Ageing and Development, vol. 135, pp. 15-23, 2014.

[24] E. G. Lakatta, "Arterial and cardiac aging: major shareholders in cardiovascular disease enterprises. Part III: cellular and molecular clues to heart and arterial aging," Circulation, vol. 107, no. 3, pp. 490-497, 2003.

[25] S. Taddei, A. Virdis, L. Ghiadoni et al., "Age-related reduction of NO availability and oxidative stress in humans," Hypertension, vol. 38, no. 2, pp. 274-279, 2001. 
[26] A. R. Smith, F. Visioli, B. Frei, and T. M. Hagen, "Age-related changes in endothelial nitric oxide synthase phosphorylation and nitric oxide dependent vasodilation: evidence for a novel mechanism involving sphingomyelinase and ceramideactivated phosphatase 2A," Aging Cell, vol. 5, no. 5, pp. 391-400, 2006.

[27] Y. Maruyama, "Aging and arterial-cardiac interactions in the elderly," International Journal of Cardiology, vol. 155, no. 1, pp. 14-19, 2012.

[28] A. U. Ferrari, A. Radaelli, and M. Centola, "Invited review: aging and the cardiovascular system," Journal of Applied Physiology, vol. 95, no. 6, pp. 2591-2597, 2003.

[29] S. Boudina, "Cardiac aging and insulin resistance: could insulin/insulin-like growth factor (IGF) signaling be used as a therapeutic target?" Current Pharmaceutical Design, vol. 19, no. 32, pp. 5684-5694, 2013.

[30] E. G. Lakatta and D. Levy, "Arterial and cardiac aging: major shareholders in cardiovascular disease enterprises: part II: the aging heart in health: links to heart disease," Circulation, vol. 107, no. 2, pp. 346-354, 2003.

[31] A. Younes, M. O. Boluyt, L. O'Neill, A. L. Meredith, M. T. Crow, and E. G. Lakatta, "Age-associated increase in rat ventricular ANP gene expression correlates with cardiac hypertrophy," American Journal of Physiology, vol. 269, no. 3, pp. H1003H1008, 1995.

[32] J. L. Caffrey, M. O. Boluyt, A. Younes et al., "Aging, cardiac proenkephalin mRNA and enkephalin peptides in the fisher 344 rat," Journal of Molecular and Cellular Cardiology, vol. 26, no. 6, pp. 701-711, 1994.

[33] D. Harman, "Aging: a theory based on free radical and radiation chemistry," Journal of Gerontology, vol. 11, no. 3, pp. 298-300, 1956.

[34] M. M. Bachschmid, S. Schildknecht, R. Matsui et al., "Vascular aging: chronic oxidative stress and impairment of redox signaling-consequences for vascular homeostasis and disease," Annals of Medicine, vol. 45, no. 1, pp. 17-36, 2013.

[35] T. Rassaf, N. S. Bryan, R. E. Maloney et al., "NO adducts in mammalian red blood cells: too much or too little?" Nature Medicine, vol. 9, no. 5, pp. 481-482, 2003.

[36] B. C. Capell, F. S. Collins, and E. G. Nabel, "Mechanisms of cardiovascular disease in accelerated aging syndromes," Circulation Research, vol. 101, no. 1, pp. 13-26, 2007.

[37] F. Mármol, J. Sánchez, D. López et al., "Loss of adaptation to oxidative stress as a mechanism for aortic damage in aging rats," Journal of Physiology and Biochemistry, vol. 63, no. 3, pp. 239247, 2007.

[38] A. Csiszar, Z. Ungvari, A. Koller, J. G. Edwards, and G. Kaley, "Aging-induced proinflammatory shift in cytokine expression profile in coronary arteries," The FASEB Journal, vol. 17, no. 9, pp. 1183-1185, 2003.

[39] P. Francia, C. Delli Gatti, M. Bachschmid et al., "Deletion of p66 $6^{\text {shc }}$ gene protects against age-related endothelial dysfunction," Circulation, vol. 110, no. 18, pp. 2889-2895, 2004.

[40] L. Rodríguez-Mañas, M. El-Assar, S. Vallejo et al., "Endothelial dysfunction in aged humans is related with oxidative stress and vascular inflammation," Aging Cell, vol. 8, no. 3, pp. 226-238, 2009.

[41] M. El Assar, J. Angulo, and L. Rodríguez-Mañas, "Oxidative stress and vascular inflammation in aging," Free Radical Biology \& Medicine, vol. 65, pp. 380-401, 2013.
[42] A. Lerman and A. M. Zeiher, "Endothelial function: cardiac events," Circulation, vol. 111, no. 3, pp. 363-368, 2005.

[43] S. Wu, Y. Ruan, M. Yin, and W. Lai, "Research on the agerelated changes in the nitric oxide pathway in the arteries of rats and the intervention effect of dehydroepiandrosterone," Gerontology, vol. 53, no. 4, pp. 234-237, 2007.

[44] A. Abudukadier, Y. Fujita, A. Obara et al., "Tetrahydrobiopterin has a glucose-lowering effect by suppressing hepatic gluconeogenesis in an endothelial nitric oxide synthase-dependent manner in diabetic mice," Diabetes, vol. 62, no. 9, pp. 3033-3043, 2013.

[45] Y. Higashi, S. Sasaki, K. Nakagawa et al., “Tetrahydrobiopterin improves aging-related impairment of endothelium-dependent vasodilation through increase in nitric oxide production," Atherosclerosis, vol. 186, no. 2, pp. 390-395, 2006.

[46] M. F. O’Rourke, M. E. Safar, and V. Dzau, “The Cardiovascular Continuum extended: aging effects on the aorta and microvasculature," Vascular Medicine, vol. 15, no. 6, pp. 461-468, 2010.

[47] E. Warabi, W. Takabe, T. Minami et al., "Shear stress stabilizes NF-E2-related factor 2 and induces antioxidant genes in endothelial cells: role of reactive oxygen/nitrogen species," Free Radical Biology and Medicine, vol. 42, no. 2, pp. 260-269, 2007.

[48] Z. Ungvari, L. Bailey-Downs, D. Sosnowska et al., "Vascular oxidative stress in aging: a homeostatic failure due to dysregulation of NRF2-mediated antioxidant response," American Journal of Physiology-Heart and Circulatory Physiology, vol. 301, no. 2, pp. H363-H372, 2011.

[49] M. N. Valcarcel-Ares, T. Gautam, J. P. Warrington et al., "Disruption of Nrf2 signaling impairs angiogenic capacity of endothelial cells: implications for microvascular aging," Journals of Gerontology A: Biological Sciences and Medical Sciences, vol. 67, no. 8, pp. 821-829, 2012.

[50] S. S. Gounder, S. Kannan, D. Devadoss et al., "Impaired transcriptional activity of $\mathrm{Nrf} 2$ in age-related myocardial oxidative stress is reversible by moderate exercise training," PLoS ONE, vol. 7, no. 9, Article ID e45697, 2012.

[51] F. M. Faraci and S. P. Didion, "Vascular protection: superoxide dismutase isoforms in the vessel wall," Arteriosclerosis, Thrombosis, and Vascular Biology, vol. 24, no. 8, pp. 1367-1373, 2004.

[52] L. Miao and D. K. St Clair, "Regulation of superoxide dismutase genes: implications in disease," Free Radical Biology and Medicine, vol. 47, no. 4, pp. 344-356, 2009.

[53] K. N. Lewis, J. Mele, P. J. Hornsby, and R. Buffenstein, "Stress resistance in the naked mole-rat: the bare essentials: A minireview," Gerontology, vol. 58, no. 5, pp. 453-462, 2012.

[54] P. Wenzel, S. Schuhmacher, J. Kienhöfer et al., "Manganese superoxide dismutase and aldehyde dehydrogenase deficiency increase mitochondrial oxidative stress and aggravate agedependent vascular dysfunction," Cardiovascular Research, vol. 80, no. 2, pp. 280-289, 2008.

[55] T. He, M. J. Joyner, and Z. S. Katusic, "Aging decreases expression and activity of glutathione peroxidase-1 in human endothelial progenitor cells," Microvascular Research, vol. 78, no. 3, pp. 447-452, 2009.

[56] G. L. Pierce, A. J. Donato, T. J. Larocca, I. Eskurza, A. E. Silver, and D. R. Seals, "Habitually exercising older men do not demonstrate age-associated vascular endothelial oxidative stress," Aging Cell, vol. 10, no. 6, pp. 1032-1037, 2011.

[57] S. Thangaswamy, E. A. Bridenbaugh, and A. A. Gashev, "Evidence of increased oxidative stress in aged mesenteric lymphatic 
vessels," Lymphatic Research and Biology, vol. 10, no. 2, pp. 5362, 2012.

[58] T. D. Oury, B. J. Day, and J. D. Crapo, "Extracellular superoxide dismutase: a regulator of nitric oxide bioavailability," Laboratory Investigation, vol. 75, no. 5, pp. 617-636, 1996.

[59] D. D. Lund, Y. Chu, J. D. Miller, and D. D. Heistad, "Protective effect of extracellular superoxide dismutase on endothelial function during aging," American Journal of Physiology: Heart and Circulatory Physiology, vol. 296, no. 6, pp. H1920-H1925, 2009.

[60] F. Mechta-Grigoriou, D. Gerald, and M. Yaniv, "The mammalian Jun proteins: redundancy and specificity," Oncogene, vol. 20, no. 19, pp. 2378-2389, 2001.

[61] J. M. Hernandez, D. H. Floyd, K. N. Weilbaecher, P. L. Green, and K. Boris-Lawrie, "Multiple facets of junD gene expression are atypical among AP-1 family members," Oncogene, vol. 27, no. 35, pp. 4757-4767, 2008.

[62] D. Gerald, E. Berra, Y. M. Frapart et al., "JunD reduces tumor angiogenesis by protecting cells from oxidative stress," Cell, vol. 118, no. 6, pp. 781-794, 2004.

[63] F. Paneni, E. Osto, S. Costantino et al., "Deletion of the activated protein-1 transcription factor JunD induces oxidative stress and accelerates age-related endothelial dysfunction," Circulation, vol. 127, no. 11, pp. 1229-1240, 2013.

[64] R. Ricci, U. Eriksson, G. Y. Oudit et al., "Distinct functions of junD in cardiac hypertrophy and heart failure," Genes and Development, vol. 19, no. 2, pp. 208-213, 2005.

[65] F. Cosentino, P. Francia, G. G. Camici, P. G. Pelicci, and T. F. Lüscher, "Final common molecular pathways of aging and cardiovascular disease: role of the p66Shc protein," Arteriosclerosis, Thrombosis, and Vascular Biology, vol. 28, no. 4, pp. 622-628, 2008.

[66] S. C. Ranieri, S. Fusco, and G. Pani, "p66 ${ }^{\text {ShcA }}$ : linking mammalian longevity with obesity-induced insulin resistance," Vitamins and Hormones, vol. 91, pp. 219-241, 2013.

[67] M. Rota, N. LeCapitaine, T. Hosoda et al., "Diabetes promotes cardiac stem cell aging and heart failure, which are prevented by deletion of the p66shc gene," Circulation Research, vol. 99, no. 1, pp. 42-52, 2006.

[68] F. C. Franzeck, D. Hof, R. D. Spescha et al., "Expression of the aging gene p66Shc is increased in peripheral blood monocytes of patients with acute coronary syndrome but not with stable coronary artery disease," Atherosclerosis, vol. 220, no. 1, pp. 282286, 2012.

[69] M. De la Fuente, "Effects of antioxidants on immune system ageing," European Journal of Clinical Nutrition, vol. 56, supplement 3, pp. S5-S8, 2002.

[70] M. de La Fuente and J. Miquel, "An update of the oxidationinflammation theory of aging: the involvement of the immune system in Oxi-Inflamm-Aging," Current Pharmaceutical Design, vol. 15, no. 26, pp. 3003-3026, 2009.

[71] T. Fulop, A. Khalil, and A. Larbi, "The role of elastin peptides in modulating the immune response in aging and age-related diseases," Pathologie Biologie, vol. 60, no. 1, pp. 28-33, 2012.

[72] A. Virdis, U. Dell'agnello, and S. Taddei, "Impact of inflammation on vascular disease in hypertension," Maturitas, vol. 78, no. 3, pp. 179-183, 2014.

[73] N. Douziech, I. Seres, A. Larbi et al., "Modulation of human lymphocyte proliferative response with aging," Experimental Gerontology, vol. 37, no. 2-3, pp. 369-387, 2002.
[74] A. Wikby, B. Johansson, J. Olsson, S. Löfgren, B. Nilsson, and F. Ferguson, "Expansions of peripheral blood CD8 T-lymphocyte subpopulations and an association with cytomegalovirus seropositivity in the elderly: the Swedish NONA immune study," Experimental Gerontology, vol. 37, no. 2-3, pp. 445-453, 2002.

[75] R. Ross, "The pathogenesis of atherosclerosis-an update," The New England Journal of Medicine, vol. 314, no. 8, pp. 488-499, 1986.

[76] P. Libby, P. M. Ridker, and G. K. Hansson, "Inflammation in atherosclerosis: from pathophysiology to practice," Journal of the American College of Cardiology, vol. 54, no. 23, pp. 21292138, 2009.

[77] V. O. Puntmann, P. C. Taylor, and M. Mayr, "Coupling vascular and myocardial inflammatory injury into a common phenotype of cardiovascular dysfunction: systemic inflammation and aging-a mini-review," Gerontology, vol. 57, no. 4, pp. 295-303, 2011.

[78] D. P. Mason, R. D. Kenagy, D. Hasenstab et al., "Matrix metalloproteinase- 9 overexpression enhances vascular smooth muscle cell migration and alters remodeling in the injured rat carotid artery," Circulation Research, vol. 85, no. 12, pp. 11791185, 1999.

[79] R. R. S. Packard and P. Libby, "Inflammation in atherosclerosis: from vascular biology to biomarker discovery and risk prediction," Clinical Chemistry, vol. 54, no. 1, pp. 24-38, 2008.

[80] T. Dawood and M. P. Schlaich, "Mediators of target organ damage in hypertension: focus on obesity associated factors and inflammation," Minerva Cardioangiologica, vol. 57, no. 6, pp. 687-704, 2009.

[81] D. G. Harrison, T. J. Guzik, H. E. Lob et al., "Inflammation, immunity, and hypertension," Hypertension, vol. 57, no. 2, pp. 132-140, 2011.

[82] C. De Ciuceis, F. Amiri, P. Brassard, D. H. Endemann, R. M. Touyz, and E. L. Schiffrin, "Reduced vascular remodeling, endothelial dysfunction, and oxidative stress in resistance arteries of angiotensin II-infused macrophage colony-stimulating factor-deficient mice: evidence for a role in inflammation in angiotensin-induced vascular injury," Arteriosclerosis, Thrombosis, and Vascular Biology, vol. 25, no. 10, pp. 2106-2113, 2005.

[83] E. A. Ko, F. Amiri, N. R. Pandey et al., "Resistance artery remodeling in deoxycorticosterone acetate-salt hypertension is dependent on vascular inflammation: evidence from mCSF-deficient mice," American Journal of Physiology-Heart and Circulatory Physiology, vol. 292, no. 4, pp. H1789-H1795, 2007.

[84] R. M. Touyz, "Reactive oxygen species, vascular oxidative stress, and redox signaling in hypertension: what is the clinical significance?" Hypertension, vol. 44, no. 3, pp. 248-252, 2004.

[85] A. Virdis, M. F. Neves, F. Amiri, R. M. Touyz, and E. L. Schiffrin, "Role of $\mathrm{NAD}(\mathrm{P}) \mathrm{H}$ oxidase on vascular alterations in angiotensin II-infused mice," Journal of Hypertension, vol. 22, no. 3, pp. 535-542, 2004.

[86] C. Vlachopoulos, K. Aznaouridis, and C. Stefanadis, "Prediction of cardiovascular events and all-cause mortality with arterial stiffness: a systematic review and meta-analysis," Journal of the American College of Cardiology, vol. 55, no. 13, pp. 1318$1327,2010$.

[87] C. Tsioufis, K. Dimitriadis, M. Selima et al., "Low-grade inflammation and hypoadiponectinaemia have an additive detrimental effect on aortic stiffness in essential hypertensive patients," European Heart Journal, vol. 28, no. 9, pp. 1162-1169, 2007. 
[88] A. S. Go, E. M. Hylek, K. A. Phillips et al., "Prevalence of diagnosed atrial fibrillation in adults: national implications for rhythm management and stroke prevention: the anticoagulation and risk factors in atrial fibrillation (ATRIA) study," Journal of the American Medical Association, vol. 285, no. 18, pp. 23702375, 2001.

[89] P. M. Ridker, M. Cushman, M. J. Stampfer, R. P. Tracy, and C. H. Hennekens, "Inflammation, aspirin, and the risk of cardiovascular disease in apparently healthy men," The New England Journal of Medicine, vol. 336, no. 14, pp. 973-979, 1997.

[90] D. Conen, P. M. Ridker, B. M. Everett et al., "A multimarker approach to assess the influence of inflammation on the incidence of atrial fibrillation in women," European Heart Journal, vol. 31, no. 14, pp. 1730-1736, 2010.

[91] M. A. Gonzalez-Gay, C. Gonzalez-Juanatey, A. Piñeiro, C. Garcia-Porrua, A. Testa, and J. Llorca, "High-grade C-reactive protein elevation correlates with accelerated atherogenesis in patients with rheumatoid arthritis," The Journal of Rheumatology, vol. 32, no. 7, pp. 1219-1223, 2005.

[92] P. E. Lazzerini, P. L. Capecchi, M. Acampa et al., "Arrhythmic risk in rheumatoid arthritis: the driving role of systemic inflammation," Autoimmunity Reviews, 2014.

[93] P. Libby, "Role of inflammation in atherosclerosis associated with rheumatoid arthritis," The American Journal of Medicine, vol. 121, no. 10, supplement 1, pp. S21-S31, 2008.

[94] V. A. Triant, H. Lee, C. Hadigan, and S. K. Grinspoon, "Increased acute myocardial infarction rates and cardiovascular risk factors among patients with human immunodeficiency virus disease," Journal of Clinical Endocrinology and Metabolism, vol. 92, no. 7, pp. 2506-2512, 2007.

[95] S. Lang, M. Mary-Krause, L. Cotte et al., "Increased risk of myocardial infarction in HIV-infected patients in France, relative to the general population," AIDS, vol. 24, no. 8, pp. 1228-1230, 2010.

[96] A. D. Nordell, M. Mckenna, A. H. Borges et al., "Severity of cardiovascular disease outcomes among patients with HIV is related to markers of inflammation and coagulation," Journal of the American Heart Association, vol. 3, no. 3, 2014.

[97] R. S. Vasan, L. M. Sullivan, R. Roubenoff et al., "Inflammatory markers and risk of heart failure in elderly subjects without prior myocardial infarction: the Framingham heart study," Circulation, vol. 107, no. 11, pp. 1486-1491, 2003.

[98] P. M. Ridker, C. H. Hennekens, J. E. Buring, and N. Rifai, "C-reactive protein and other markers of inflammation in the prediction of cardiovascular disease in women," The New England Journal of Medicine, vol. 342, no. 12, pp. 836-843, 2000.

[99] P. M. Ridker, N. Rifai, M. J. Stampfer, and C. H. Hennekens, "Plasma concentration of interleukin-6 and the risk of future myocardial infarction among apparently healthy men," Circulation, vol. 101, no. 15, pp. 1767-1772, 2000.

[100] L. H. Kuller, R. P. Tracy, J. Shaten, and E. N. Meilahn, "Relation of C-reactive protein and coronary heart disease in the MRFIT nested case-control study," American Journal of Epidemiology, vol. 144, no. 6, pp. 537-547, 1996.

[101] "Executive summary of the third report of the National Cholesterol Education Program (NCEP) expert panel on detection, evaluation, and treatment of high blood cholesterol in adults (adult treatment panel III)," The Journal of the American Medical Association, vol. 285, no. 19, pp. 2486-2497, 2001.
[102] P. M. Ridker, N. Rifai, L. Rose, J. E. Buring, and N. R. Cook, "Comparison of C-reactive protein and low-density lipoprotein cholesterol levels in the prediction of first cardiovascular events," The New England Journal of Medicine, vol. 347, no. 20, pp. 1557-1565, 2002.

[103] J. Coppé, C. K. Patil, F. Rodier et al., "A human-like senescenceassociated secretory phenotype is conserved in mouse cells dependent on physiological oxygen," PLoS ONE, vol. 5, no. 2, Article ID e9188, 2010.

[104] A. Freund, A. V. Orjalo, P. Desprez, and J. Campisi, "Inflammatory networks during cellular senescence: causes and consequences," Trends in Molecular Medicine, vol. 16, no. 5, pp. 238246, 2010.

[105] M. Wang, R. E. Monticone, and E. G. Lakatta, "Arterial aging: a journey into subclinical arterial disease," Current Opinion in Nephrology and Hypertension, vol. 19, no. 2, pp. 201-207, 2010.

[106] M. Wang, J. Zhang, G. Spinetti et al., "Angiotensin II activates matrix metalloproteinase type II and mimics age-associated carotid arterial remodeling in young rats," The American Journal of Pathology, vol. 167, no. 5, pp. 1429-1442, 2005.

[107] E. G. Lakatta, M. Wang, and S. S. Najjar, "Arterial aging and subclinical arterial disease are fundamentally intertwined at macroscopic and molecular levels," The Medical Clinics of North America, vol. 93, no. 3, pp. 583-604, 2009.

[108] G. Corbi, V. Conti, G. Scapagnini, A. Filippelli, and N. Ferrara, "Role of sirtuins, calorie restriction and physical activity in aging," Frontiers in Bioscience -Elite, vol. 4, no. 2, pp. 768-778, 2012.

[109] A. Salminen, J. Huuskonen, J. Ojala, A. Kauppinen, K. Kaarniranta, and T. Suuronen, "Activation of innate immunity system during aging: NF-kB signaling is the molecular culprit of inflamm-aging," Ageing Research Reviews, vol. 7, no. 2, pp. 83$105,2008$.

[110] E. Cevenini, D. Monti, and C. Franceschi, "Inflamm-ageing," Current Opinion in Clinical Nutrition and Metabolic Care, vol. 16, no. 1, pp. 14-20, 2013.

[111] H. Y. Cohen, C. Miller, K. J. Bitterman et al., "Calorie restriction promotes mammalian cell survival by inducing the SIRT1 deacetylase," Science, vol. 305, no. 5682, pp. 390-392, 2004.

[112] A. Salminen, A. Kauppinen, T. Suuronen, and K. Kaarniranta, "SIRT1 longevity factor suppresses NF- $\kappa \mathrm{B}$-driven immune responses: regulation of aging via NF- $\kappa \mathrm{B}$ acetylation?" BioEssays, vol. 30, no. 10, pp. 939-942, 2008.

[113] A. Salminen, J. Ojala, J. Huuskonen, A. Kauppinen, T. Suuronen, and K. Kaarniranta, "Interaction of aging-associated signaling cascades: inhibition of NF- $\kappa \mathrm{B}$ signaling by longevity factors FoxOs and SIRT1," Cellular and Molecular Life Sciences, vol. 65, no. 7-8, pp. 1049-1058, 2008.

[114] X. Y. Liu, Q. Wang, S. J. Xia, J. Huang, Z. Shen, and H. Xu, “Characteristics of lymphocyte nuclear factor- $\kappa \mathrm{B}$ signal transduction kinase expression in aging process and regulatory effect of epimedium flavonoids," Chinese Journal of Integrative Medicine, vol. 17, no. 9, pp. 704-709, 2011.

[115] K. Breving and A. Esquela-Kerscher, "The complexities of microRNA regulation: mirandering around the rules," International Journal of Biochemistry and Cell Biology, vol. 42, no. 8, pp. 1316-1329, 2010.

[116] F. Olivieri, R. Lazzarini, R. Recchioni et al., "MiR-146a as marker of senescence-associated pro-inflammatory status in 
cells involved in vascular remodelling," Age, vol. 35, no. 4, pp. 1157-1172, 2012.

[117] J. K. Kundu and Y.-J. Surh, "Emerging avenues linking inflammation and cancer," Free Radical Biology \& Medicine, vol. 52, no. 9, pp. 2013-2037, 2012.

[118] M. Fabbri, A. Paone, F. Calore et al., "MicroRNAs bind to Tolllike receptors to induce prometastatic inflammatory response," Proceedings of the National Academy of Sciences of the United States of America, vol. 109, no. 31, pp. E2110-E2116, 2012.

[119] F. Olivieri, M. R. Rippo, V. Monsurrò et al., "MicroRNAs linking inflamm-aging, cellular senescence and cancer," Ageing Research Reviews, vol. 12, no. 4, pp. 1056-1068, 2013.

[120] Y. Hasegawa, T. Saito, T. Ogihara et al., "Blockade of the nuclear factor- $\kappa \mathrm{B}$ pathway in the endothelium prevents insulin resistance and prolongs life spans," Circulation, vol. 125, no. 9, pp. 1122-1133, 2012.

[121] F. Paneni, J. A. Beckman, M. A. Creager, and F. Cosentino, "Diabetes and vascular disease: pathophysiology, clinical consequences, and medical therapy: part I," European Heart Journal, vol. 34, no. 31, pp. 2436-2446, 2013.

[122] A. J. Donato, G. L. Pierce, L. A. Lesniewski, and D. R. Seals, "Role of NF $\kappa$ B in age-related vascular endothelial dysfunction in humans," Aging, vol. 1, no. 8, pp. 678-680, 2009.

[123] R. Weindruch and R. S. Sohal, "Seminars in medicine of the Beth Israel Deaconess Medical Center. Caloric intake and aging," The New England Journal of Medicine, vol. 337, no. 14, pp. 986-994, 1997.

[124] Z. Ungvari, C. Parrado-Fernandez, A. Csiszar, and R. de Cabo, "Mechanisms underlying caloric restriction and lifespan regulation: implications for vascular aging," Circulation Research, vol. 102, no. 5, pp. 519-529, 2008.

[125] S. Stein, N. Schäfer, A. Breitenstein et al., "SIRT1 reduces endothelial activation without affecting vascular function in ApoE-/- mice," Aging, vol. 2, no. 6, pp. 353-360, 2010.

[126] A. J. Donato, A. E. Walker, K. A. Magerko et al., "Life-long caloric restriction reduces oxidative stress and preserves nitric oxide bioavailability and function in arteries of old mice," Aging Cell, vol. 12, no. 5, pp. 772-783, 2013.

[127] K. J. Pearson, K. N. Lewis, N. L. Price et al., "Nrf2 mediates cancer protection but not prolongevity induced by caloric restriction," Proceedings of the National Academy of Sciences of the United States of America, vol. 105, no. 7, pp. 2325-2330, 2008.

[128] L. Guarente and F. Picard, "Calorie restriction-the SIR2 connection,” Cell, vol. 120, no. 4, pp. 473-482, 2005.

[129] H. Yao and I. Rahman, "Perspectives on translational and therapeutic aspects of SIRT1 in inflammaging and senescence," Biochemical Pharmacology, vol. 84, no. 10, pp. 1332-1339, 2012.

[130] E. Nisoli, C. Tonello, A. Cardile et al., "Cell biology: calorie restriction promotes mitochondrial biogenesis by inducing the expression of eNOS," Science, vol. 310, no. 5746, pp. 314-317, 2005.

[131] A. Csiszar, N. Labinskyy, R. Jimenez et al., "Anti-oxidative and anti-inflammatory vasoprotective effects of caloric restriction in aging: role of circulating factors and SIRT1," Mechanisms of Ageing and Development, vol. 130, no. 8, pp. 518-527, 2009.

[132] B. van der Loo, R. Labugger, J. N. Skepper et al., "Enhanced peroxynitrite formation is associated with vascular aging," The Journal of Experimental Medicine, vol. 192, no. 12, pp. 1731-1743, 2000.
[133] Q. Zhang, Z. Wang, H. Chen et al., "Endothelium-specific overexpression of class III deacetylase SIRT1 decreases atherosclerosis in apolipoprotein E-deficient mice," Cardiovascular Research, vol. 80, no. 2, pp. 191-199, 2008.

[134] J. A. Baur and D. A. Sinclair, "Therapeutic potential of resveratrol: the in vivo evidence," Nature Reviews Drug Discovery, vol. 5, no. 6, pp. 493-506, 2006.

[135] Z. Ungvari, Z. Orosz, A. Rivera et al., "Resveratrol increases vascular oxidative stress resistance," American Journal of Physiology: Heart and Circulatory Physiology, vol. 292, no. 5, pp. H2417H2424, 2007.

[136] E. N. Frankel, A. L. Waterhouse, and J. E. Kinsella, "Inhibition of human LDL oxidation by resveratrol," The Lancet, vol. 341, no. 8852, pp. 1103-1104, 1993.

[137] U. G. B. Haider, T. U. Roos, M. I. Kontaridis et al., "Resveratrol inhibits angiotensin II- and epidermal growth factor-mediated Akt activation: role of Gab1 and Shp2," Molecular Pharmacology, vol. 68, no. 1, pp. 41-48, 2005.

[138] A. Csiszar, K. Smith, N. Labinskyy, Z. Orosz, A. Rivera, and Z. Ungvari, "Resveratrol attenuates TNF- $\alpha$-induced activation of coronary arterial endothelial cells: role of NF- $\kappa \mathrm{B}$ inhibition," The American Journal of Physiology-Heart and Circulatory Physiology, vol. 291, no. 4, pp. H1694-H1699, 2006.

[139] G. Arunachalam, H. Yao, I. K. Sundar, S. Caito, and I. Rahman, "SIRT1 regulates oxidant- and cigarette smoke-induced eNOS acetylation in endothelial cells: role of resveratrol," Biochemical and Biophysical Research Communications, vol. 393, no. 1, pp. 66-72, 2010. 


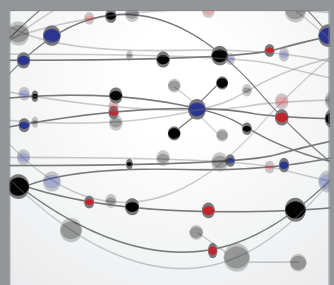

The Scientific World Journal
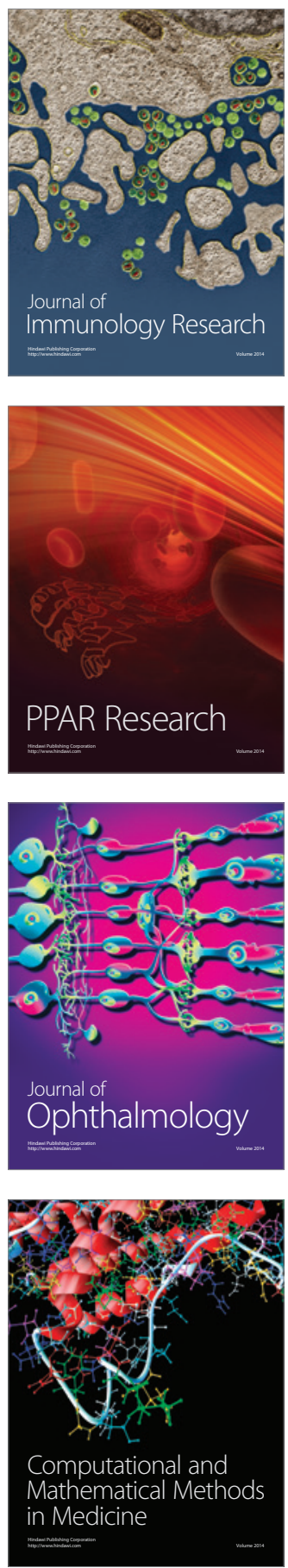

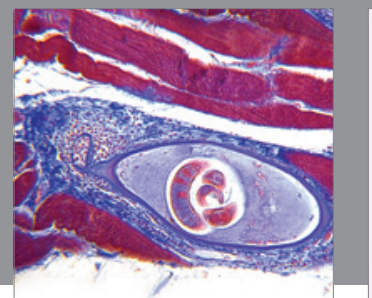

Gastroenterology

Research and Practice
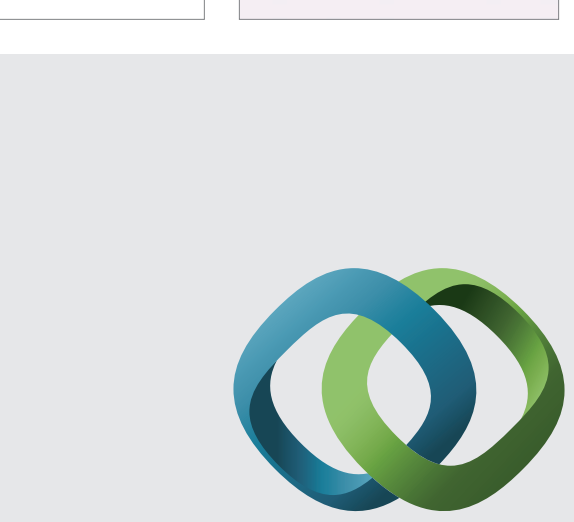

\section{Hindawi}

Submit your manuscripts at

http://www.hindawi.com
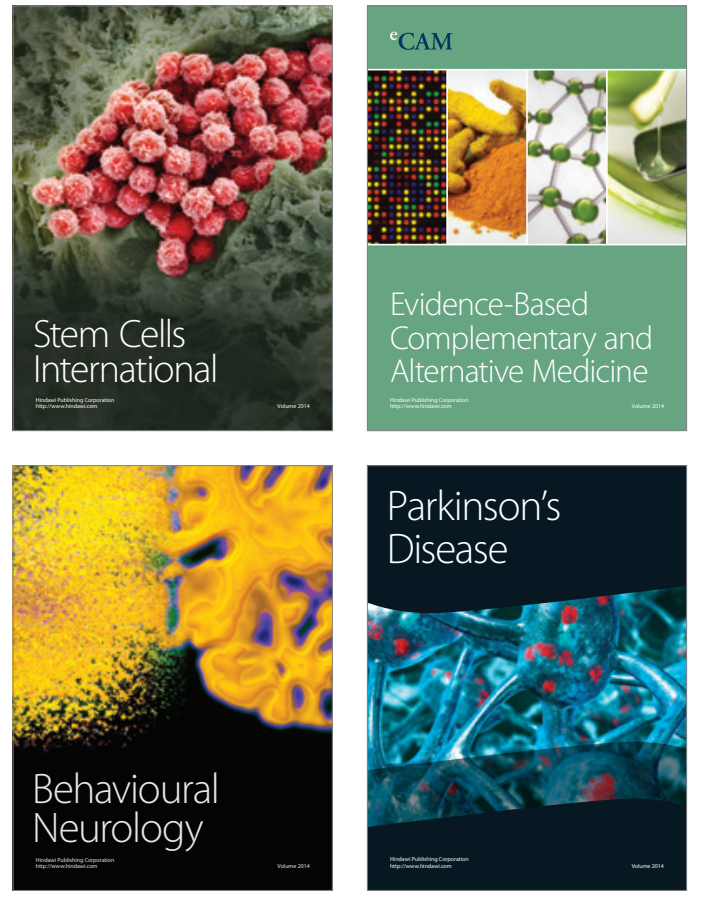
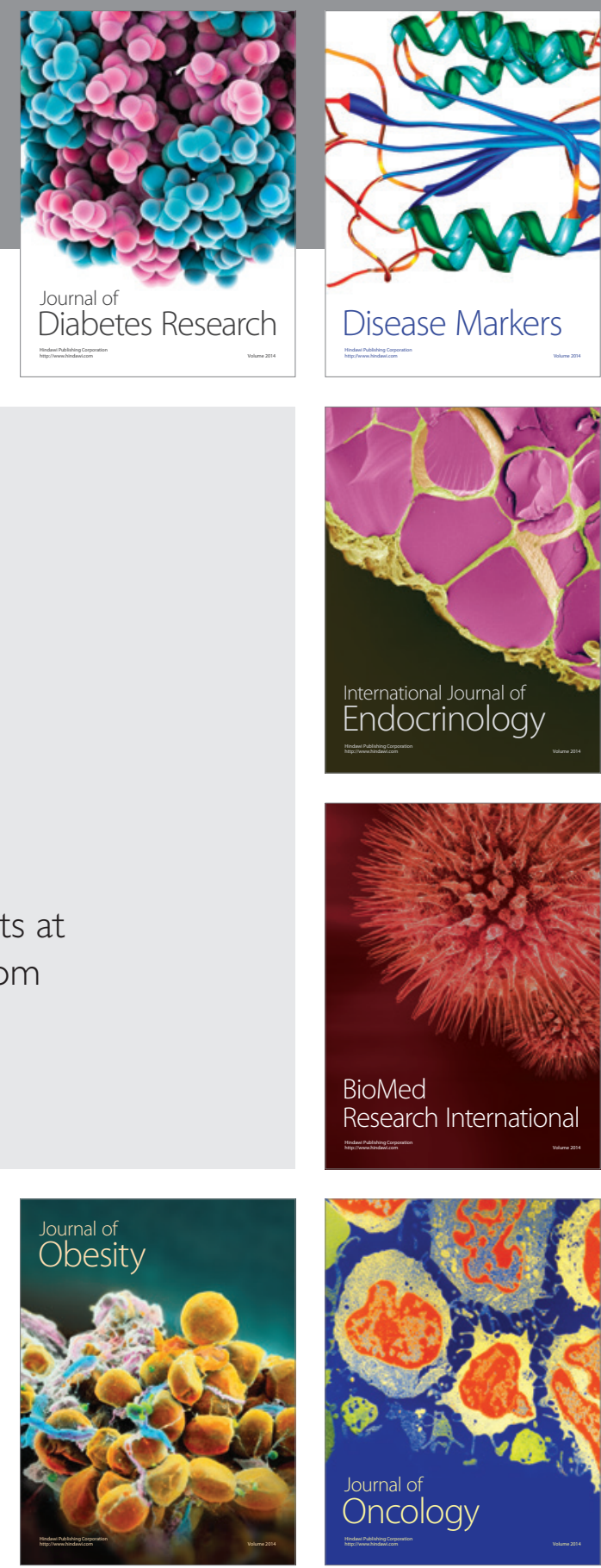

Disease Markers
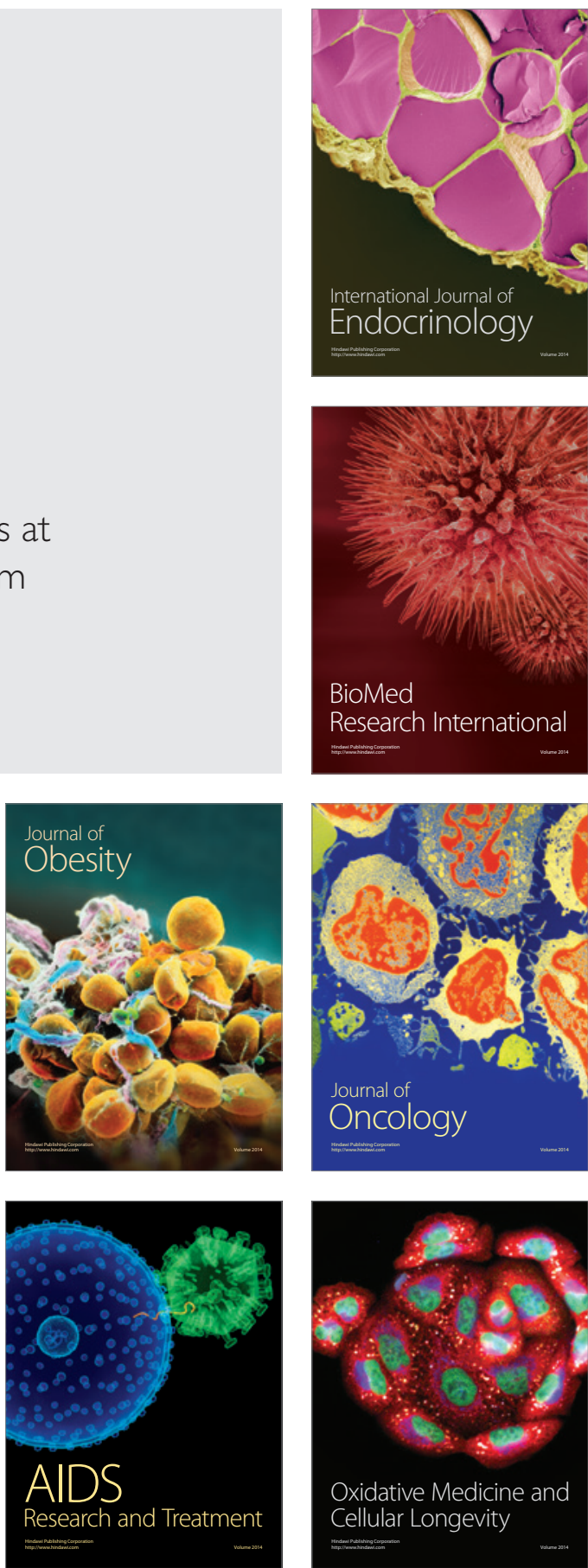